\title{
How Do Online Education Companies Acquire Heterogeneous Innovative Elements? An Open Innovation Theory Perspective
}

\author{
Xun Huang \\ Sichuan Radio and TV University, Chengdu 610073, China. \\ huangxun@scrtvu.net
}

\begin{abstract}
Keywords: Market competition, heterogeneous elements of innovation, online education companies, the open innovation theory.
\end{abstract}

\begin{abstract}
Competition is the eternal theme of the commercial market. A large number of online education companies have been established. Acquiring heterogeneous innovative elements is the foundation for the firms to gain competitive advantages in business. The purpose of the study is to improve the management of innovative activities in online education companies. Following the theory of open innovation, based on the urgent need of online education companies' innovative activities, this paper makes an empirical study on the acquisition of the heterogeneous innovative elements for online education companies in China. The study found that online education companies need to break the organizational boundaries to obtain heterogeneous elements of innovation. This research will help them to acquire heterogeneous innovative resources in a wider space. The typical heterogeneous innovative elements include the differentiated elements of product innovation, the differentiated elements of technological innovation, the differentiated elements of organizational innovation, and the differentiated elements of marketing innovation.
\end{abstract}

\section{Introduction}

Competition is the eternal theme of the commercial market. The new round of internet technology changes and the increasing demand for scarce and quality education services have promoted the consumers to pay for online education services. The capital market continues to be optimistic about the huge market space for online education industry. A large number of online education companies have been established. More and more firms are pouring into the online education industry. Acquiring heterogeneous innovative elements is the foundation for the online education companies to gain competitive advantage in business.

Based on the business background above, the basic question of this paper is: following the perspective of open innovation theory, how do online education companies acquire heterogeneous innovative elements such as knowledge, skills and resources?

\section{Literature References}

\subsection{Innovation Theory and the Elements of Innovation.}

The concept of "innovation" was first introduced by Joseph Schumpeter in 1911 in his book "The Theory of Economic Development ". Subsequently, the concept of innovation was introduced into the field of economic growth research. According to Schumpeter's point of view, innovation is "the establishment of a production function". Thus introducing "new combination" of production factors into production system creates extra profits

The innovative element refers to the integration of resources and abilities in the innovative activities. Resources and capacity that support innovative activities are called elements of innovation. Accordingly, the acquisition of innovative elements means acquiring the necessary resources and abilities to support innovative activities, such as technology, human resources, financial resources, information resources and so on. A company's acquisition of innovative elements is aimed to achieve the "new combinations" in subsequent processes. 
According to Joseph Schumpeter's theory of innovation, the "new combinations" includes product innovation, process innovation, marketing innovation, organizational innovation and innovation of supply source. In these processes, the acquisition of innovative elements is the basic step. From this perspective, innovative elements are the foundation of innovative activities.

There is no unified view on the classification of innovative elements in academia. Some scholars believe that the elements of innovation include the elements of innovators, the elements of innovative resources and the elements of innovative environment. The elements of innovation are defined as direct and indirect units by other scholars. The direct units include technology, human resources and the financial resources, the indirect units mainly include infrastructure, social environment and macro policy.

In this paper, heterogeneous innovative element is a kind of direct innovative elements. It refers to the innovative elements owned by a company, which is different from the innovative elements owned by other companies in the same industry. Heterogeneous innovative elements include the differentiated technologies, capabilities, knowledge and resources that are conducive to the achievement of innovative activities and the improvement of innovative performance. For example, typical heterogeneous innovative elements include the differentiated elements of product innovation, the differentiated elements of technological innovation, the differentiated elements of organizational innovation, and the differentiated elements of marketing innovation. Heterogeneous innovative elements do not include environmental elements of innovation that all companies share in the same industry, such as infrastructure, social environment and macro policies.

\subsection{Open Innovation (OI) Theory.}

Open innovation is now a widely used concept in academia, business, and policy making. Open innovation has been defined as "the use of purposive inflows and outflows of knowledge to accelerate internal innovation, and expand the markets for external use of innovation, respectively”. Thus we can break the traditional boundaries in flexible ways. In addition, we can achieve flexible acquisition, frequent flow and effective utilization of innovative elements. There are two important kinds of open innovation: outside-in and inside-out - also referred to as inbound and outbound open innovation, respectively.

In the era of knowledge economy, if the online education company only relies on the innovative elements of the internal innovation, the company will take on a huge cost. In addition, the company is unable to adapt to the rapid development of market demand and fierce competition. The concept of open innovation captures the increasing propensity of firms to look beyond their traditional boundaries of operation. Open innovation is an effective means for online education companies to acquire more innovative activities and stronger market competitiveness with faster speed and lower cost. It can be predicted that open innovation will become the leading mode of innovative activities for online education companies. The application field of open innovation theory has gradually extended from the high-tech industry to the traditional manufacturing industry. With the rising of service economy all over the world, the theory of open innovation has been penetrated into service industries such as medical treatment, design industry, tourism, internet finance, and so on.

It was found that business services were more active seekers of external knowledge than manufacturers. Online education industry is typically knowledge-intensive. In recent years, with the rapid development of online education industry, the innovative activities of online education companies have broken through the boundaries of firms in business practice. There are more and more interactive activities between online education firms and other subjects outside organization's borders.

\section{Heterogeneous Innovative Elements That Support Innovative Activities Of Online Education Companies}

The element of innovation is the source of innovative activities. Heterogeneous innovative elements refer to the differentiated technologies, abilities, knowledge and resources that are conducive to the realization of innovative activities and the improvement of innovative performance. 
In the past, companies were limited to the internal boundaries of the organization to obtain heterogeneous innovative elements. Thus a huge amount of human resources, financial costs, time costs were required.

Following the open innovation theory, online education companies acquire a wider range of the heterogeneous innovative elements to promote innovative activities. Acquisition of heterogeneous innovative elements is an effective means to improve the efficiency of innovation resource allocation and to realize innovative performance. Another advantage of acquiring heterogeneous innovative elements through open innovation is that the cost is lower and the efficiency is higher.

\subsection{Acquisition of Heterogeneous Technological Innovation Elements Based on OI Activities.}

There is no doubt that it is an important means for online education companies to enhance market competitiveness and build competitive barriers. Technological innovation is an important means to enhance the core competitiveness of firms. The necessity of technological innovation is that online education products can be more humanized and easier to interact with users.

With the emergence of new technologies and educational concepts, it is necessary to acquire and adopt heterogeneous technical innovative elements. It should be noted that the acquisition of heterogeneous technological innovative elements is also an important step for open innovative activities.

In recent years, the technological innovation of online education market in China is mainly driven by internet entrepreneurs. Other technical innovations are driven by managers with strong working background in the internet business. Generally speaking, the common way is entrepreneurial cooperation, strategic alliances, mergers and acquisitions, technology introduction, and so on. The large-scale internet enterprises and high-tech firms, such as Google, Amazon, Apple, Badu, Ten cent, Alabama, have actively participated in the online education industry. It also provides an inward-oriented open channel for online education companies to acquire heterogeneous technological innovative elements. For example, the online education company "Boxfish" announced the introduction of AI technology in 2016. The online education brand of "Liu li shoo" announced that they could use large data and algorithms to compute students' language proficiency in all aspects. The commercial organization "VIP kid" not only introduces and absorbs technological innovation, but also accelerates the reserve work of the top technical talents in the internet industry.

\subsection{Acquisition of Heterogeneous Product Innovation Elements Based on OI Activities.}

Product innovative activity is a process in which companies improve or redesign products and services that meet the needs of users in segment markets. In order to avoid the homogenization of products, online education companies need to implement innovative activities. In recent years, online education is gradually making learning activities to be a satisfying and interesting way for users with various forms of products.

Following the open innovation theory, the relevant groups in the online education service supply chain may provide heterogeneous product innovative elements for online education companies. The relevant groups include service producers (teachers, traditional education institutions and business institutions), consumers (students), customers (students or parents), other members of the service supply chain (technology providers, platform providers, scientific research institutions, etc.), and even the competitors. For example, the online education brand of "Xuebajun" provides the traditional educational institutions with "shared database for homework ", thus to achieve outbound open innovation. The online education brand of "Zuoyebang" acquires high-quality and scarce teaching resources and other heterogeneous product innovative elements in a cooperative way, so as to achieve inbound open innovation.

\subsection{Acquisition of Heterogeneous Organizational Innovation Elements Based on OI Activities.}

Online education industry has a typical knowledge intensive nature, and has extensive industrial relevance and driving force. Compared with the traditional manufacturing industry, knowledge intensive service industry is in urgent need of dynamic and continuous organizational innovation.

The organization must be constantly adjusted and transformed along with changes in external environment and internal conditions. Innovative organization has typical characteristics of learning organization. Learning organization is good at acquiring, creating and transferring heterogeneous 
innovative elements. After obtaining heterogeneous organizational innovative elements, firms can reshape the formal or informal organizational structure. Such formal or informal organizational structure is conducive to acquiring, absorbing and transforming knowledge and innovative elements. This will promote the flow of knowledge and innovation among different firms.

\subsection{Acquisition of Heterogeneous Marketing Innovation Elements Based on OI Activities.}

Marketing is an important link for firms to get profits. The changes and development of market demand require firms to continuously carry out marketing innovation. The innovative activities of marketing could gain broad space for development.

The online education industry is forming and developing. Therefore, we can make use of the latest progress in the field of marketing innovation and the mature experience of marketing business practice in all walks of life to obtain heterogeneous marketing innovative elements.

For example, the "Cctalk" online education brand offers one-stop services such as live streaming, social marketing, educational services, etc. These marketing strategies are not only conducive to the realization of product sales, but also effectively promote service promotion and brand communication. Another business case is that the big data accumulated by the online education brand of "Yiqizuoye", which can provide the basic data for its subbrand "UStalk" to achieve the precise marketing. Other brands have launched composite services to gather users and potential users. In addition, the cooperation between online education firms and customers is a new way to implement open innovation.

\section{Summary}

Today's online education service practice has been and is undergoing a series of innovative changes. The acquisition of heterogeneous innovative elements is an essential part of the innovative activities for online education companies.

From the perspective of business practice, many online education companies are trying to break the organizational boundaries and get heterogeneous innovative elements, thereby increasing the competitiveness of firms. Following the open innovation theory, acquiring heterogeneous innovative elements inside and outside the organization boundary will be a continuous activity.

\section{Acknowledgements}

2016 Annual Research Project Funded by the Education Department of Sichuan Province: Research on Online Service Strategy Based on Adult Students' Online Learning Disabilities, Number: 16SB0411.

\section{References}

[1]. Boers M, Chesbrough H, Meads C. Open Innovation: Research, Practices, and Policies. California Management Review. Vol.60 (2018), Issue 2, p5-16.

[2]. Chesbrough, H, Wimp V, Joel W, eds. Open innovation: Researching a new paradigm. Oxford University Press on Demand, 2006.

[3]. Chesbrough, Henry. Open services innovation: Rethinking your business to grow and compete in a new era. John Wiley \& Sons, 2010.

[4]. Liuxingyan, Chennai, Zhangxinting. The puling effects of innovative elements acting on emerging industry. Science \&Technology Progress Policy. Vol.28 (2001) No. 24, p.50-54.

[5]. Mina A, Bascavusoglu-Moreau E, Hughes A. Open service innovation and the firm's search for external knowledge. Research Policy. Vol. 43 (2014), Issue 5, p853-866.

[6]. Thanawala, Kishore. Schumpeter's Theory of Economic Development and Development Economics. Review of Social Economy. Vol. 52(1994), Issue 4, p353-363. 